\title{
Em defesa da memória ${ }^{+}$
}

\author{
J O R G E C A A D O *
}

\section{RAZÃO DUM TÍTULO}

Tal como quase todas as boas ideias, este título não é original. Vem dum dos meus livros de cabeceira, A Defence of Poetry (1821; publicado, 1840) do poeta romântico inglês, Percy Bysshe Shelley (1792-1822) Figura 1. O ensaio de Shelley não era propriamente uma mera defesa da poesia - pelo menos no sentido em que hoje entendemos o que é a poesia - tal como esta palestra não é apenas um ensaio sobre a memória. Shelley trata das duas classes de actividade mental - a Razão e a Imaginação. A primeira é a "enumeração de quantidades já conhecidas"; a segunda, a "percepção do valor dessas quantidades, tanto separadamente como no seu conjunto". E acrescenta: "A Razão respeita as diferenças, e a Imaginação as semelhancas das coisas. A Razão está para a Imaginação como o instrumento para o agente, o corpo para o espírito, a sombra para a substância" (os sublinhados são meus). O meu argumento é que a memória é o instrumento de detecção das semelhanças, isto é, a memória é a chave ou porta da Imaginação. Para os desmemoriados, nada é igual, tudo é diferente. A criação e a imaginação constroem-se com base nas parecenças.

Shelley fala de poesia como a "expressão da Imaginação", mas o seu raciocínio também se aplica à ciência. De facto, ele chega mesmo a afirmar que a "poesia inclui toda a ciência" e que "toda a ciência se deve reportar à poesia" . Para mim, esta última asserção representa um critério de verdade científica, no sentido einsteiniano (a velha história de que a equação tem de ser bonita, para estar certa). Shelley acha que a função da faculdade poética é dupla: "por um lado, cria novos materiais de conhecimento, poder e prazer; por outro, engendra na mente um desejo de os reproduzir e organizar de acordo com um certo ritmo e ordem, que bem podem ser chamadoso belo e o bom"

Para Shelley, "um Poema é a própria imagem da vida expressa na sua verdade universal". Por outras palavras, uma equação universal é um Poema. Tal como o poeta de Shelley, o cientista é um profeta e um legislador mundial. Pois "não só observa intensamente o presente tal como ele é, e descobre as leis segundo as quais as coisas

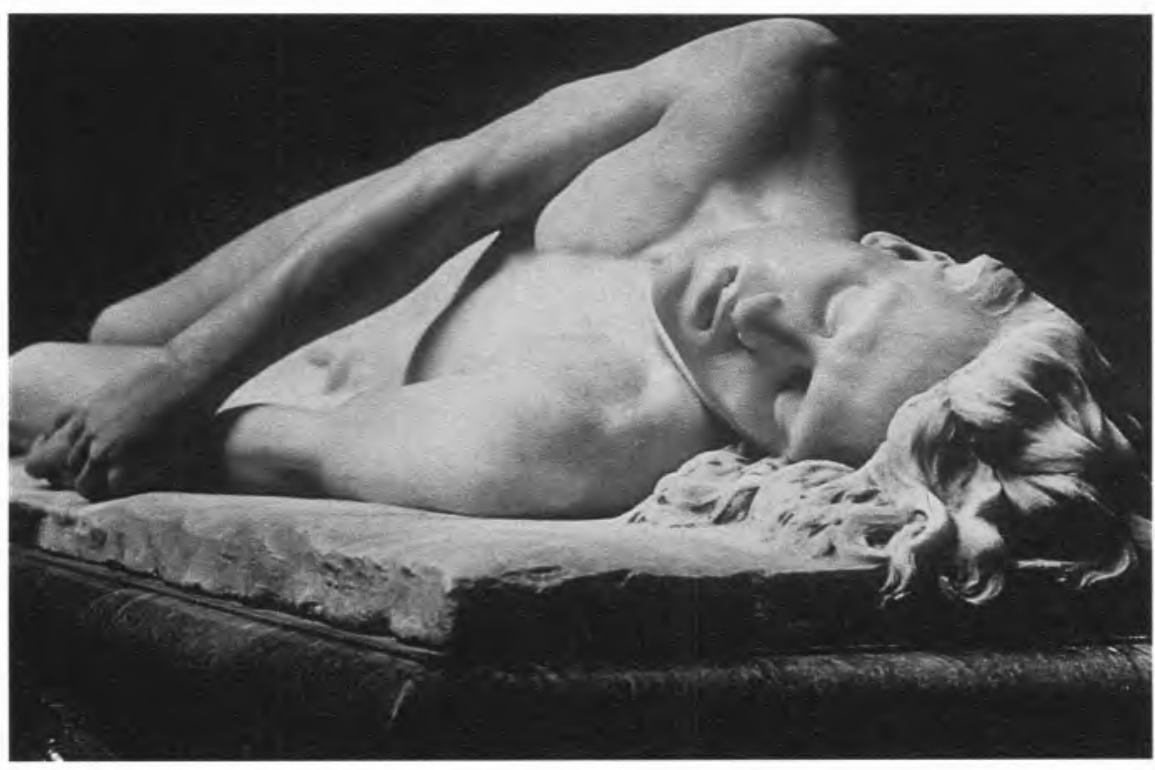

Fig. 1. - ONSLOW FORD, Shelley Memorial (1893), University College, Oxford presentes devem ser ordenadas, mas adivinha o futuro no presente, e os seus pensamentos são os germes da flor e fruto da última hora". Isto soa a capacidade preditora da ciência. Mas será que a ciência prevê? Voltarei a este ponto mais adiante.

Shelley discute ainda a afirmação de que "o exercício da imaginação é mais delicioso" mas que "o da razão é mais útil", uma dicotomia que em tempos mais recentes tem sido atribuída ao binário da arte e ciência. Mas acaba por estabelecer que "a verdadeira Utilidade está na produção e garantia desse prazer". Lord Byron (1788-1824), que discutia estas coisas com Shelley, chamou à Poesia um "fluir da lava da emoção". Para os românticos, a poesia (criação) funcionava como um motor de combustão interna com a concomitante produção de entropia.

\section{O PALÁCIO DA MEMÓRIA}

Metaforicamente falando, a memória é o músculo da imaginação que se exercita decorando. Não venho fazer uma teoria da memória. Venho, sim, fazer a apologia da memorização, do "saber de cor". É um exercício que tem de ser praticado na devida altura, na juventude, quando o corpo se treina e a mente se afina. Depois, é demasiado tarde. Até porque Shelley viu claramente que "a mente em criação é um carvão a apagar-se" com a Imaginação a ser ateada por ventos inconstantes e a morte fria como destino final. (A energia descamba inevitavelmente em entropia, ou melhor, no produto TS da temperatura pela entropia - o desespero do caos.) Quando a "composição (criação) começa, a inspiração já está em declínio" e o resultado "é provavelmente uma sombra pálida da concepção original".

Para o bem e para o mal, dou o meu exemplo. Fui daquelas crianças que, embora tivessem aprendido a ler sozinhas aos 4 ou 5 anos, tiveram também imensa dificuldade em aprender a tabuada de cor. Para minha vergonha ainda guardo essa 
velha brochura da Instrução Primária - a Tabuada - capa vermelha um tanto sebosa pelo manuseamento aturado. Hoje estou grato aos meus Pais por me terem várias vezes humilhado publicamente por não saber a tabuada de cor. Mas tive bons mestres. Mais tarde, no liceu, fui obrigado, bem contra vontade, a decorar nacos de prosa, poemas, estâncias a fio de Os Lusíadas (que Shelley cita em A Defence of Poetry, ao lado do Orlando furioso de Tasso e da Faerie Queene de Spenser). Talvez por isso não me tenha esquecido que Os Lusíadas têm X Cantos... Queixava-me de que o professor não seguia nem dava o programa, pois tudo se resumia a decorar literatura e a dividir orações. Ao menos dava-nos a possibilidade de escolher e eu, não sei bem porquê, escolhia quase sempre Padre António Vieira (1608-1697). (Eram os tempos da famosa colecção de Clássicos Sá da Costa.) Passei então a escrever ao estilo de Vieira, salvo seja, e permanece, ainda hoje, o gosto pela adjectivação. Decorava coisas como o interminável Sermão de Santo António aos Peixes (sempre fui um fã do Santo António, mas isso é outra história...). Mais tarde viria a deliciar-me com a canção de Gustav Mahler (18601911), "Des Antonius von Padua Fischpredigt" onde os peixes vêm ouvir fielmente o Santo mas não fazem caso do que ele diz (um pouco como os nossos alunos hoje em dia...).

Outro sermão de Vieira que decorei - bem mais curto, aliás - foi $\mathbf{O}$ Estatuário: "Arranca o estatuário uma pedra dessas montanhas, tosca, bruta dura, informe". Lembro-me também que só percebi o que esta frase de abertura em catadupa queria dizer quando vi, em Roma, a estatuária de Miguelângelo (1476-1564), ou melhor de seu nome Michelangiolo, para o abortado túmulo do incrível Papa Júlio II. Refiro-me, em especial, aos cativos ou escravos, semi-acabados, o corpo a emergir do mármore, tal como o espírito se solta do corpo ou a arte surge do caos. É o processo

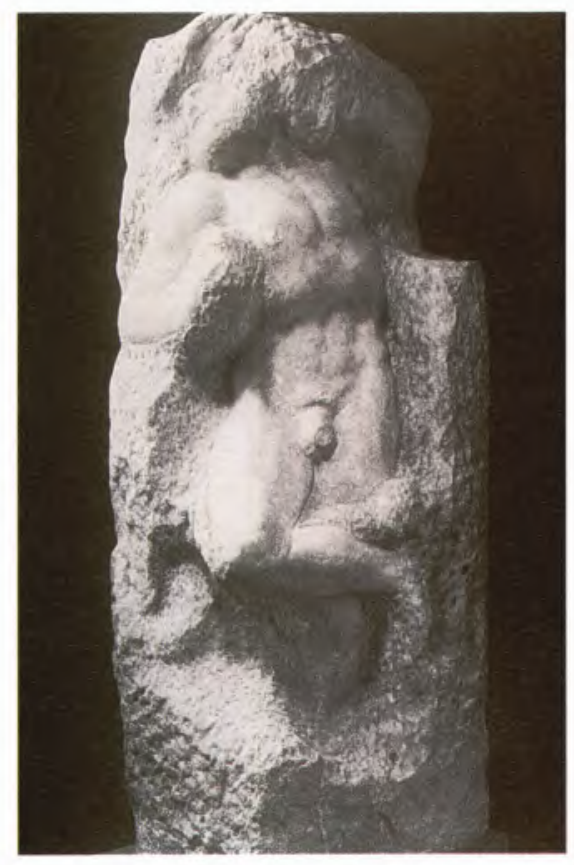

Fig. 2. - MiCHELANGIOLO, Cativo.

da pedra a tornar-se imortal, a metamorfose de Carrara em Michelangiolo - Figura 2. É, na linguagem de Shelley, a Imaginação a transcender a Razão, e aqui se vê um sopro de vida tão mágico como o dedo de Deus a tocar o de Adão - o sopro de Deus - no tecto da Capela Sistina. E foi isto, também, que uns anos mais tarde me levou a comprar uma edição italiana dos Poemas (Rime) de Michelangiolo, num exemplar que tinha pertencido ao Poeta Laureado do Reino Unido, John Masefield (1878-1967). A Imaginação é como as cerejas e procede por associações.

Que tem isto a ver com a ciência em geral, ou a química em particular? Não tem nada e tem tudo. Estou convencido de que a minha quase obsessão por exercitar a memória, decorando datas (nascimento e morte de Wagner e Verdi, Mozart e Monteverdi), decorando rios e serras, ou hoje as estações do Metro de Tóquio (Shinjuku, Yoyogi, Harajuku, Shibuya) e criando mnemónicas foi um treino essencial para o reconhecimento de estruturas e o espevitar da Imaginação. No liceu decorei os logaritmos dos nove dígitos, muito útil na época antes das calculadoras (AC) quando não tinha a régua de cálculo à mão. Como estudante de química, senti que a estrutura maior era a Tabela Periódica, e por isso tratei de a aprender de cor. Os grupos principais, tipo halogéneos, gases inertes ou metais alcalinos eram fáceis. As dificuldades estavam nas séries, por exemplo dos metais de transição ou dos lantanídeos. Vou revelar um segredo: inspirado por uma nota do Journal of Chemical Education, de-

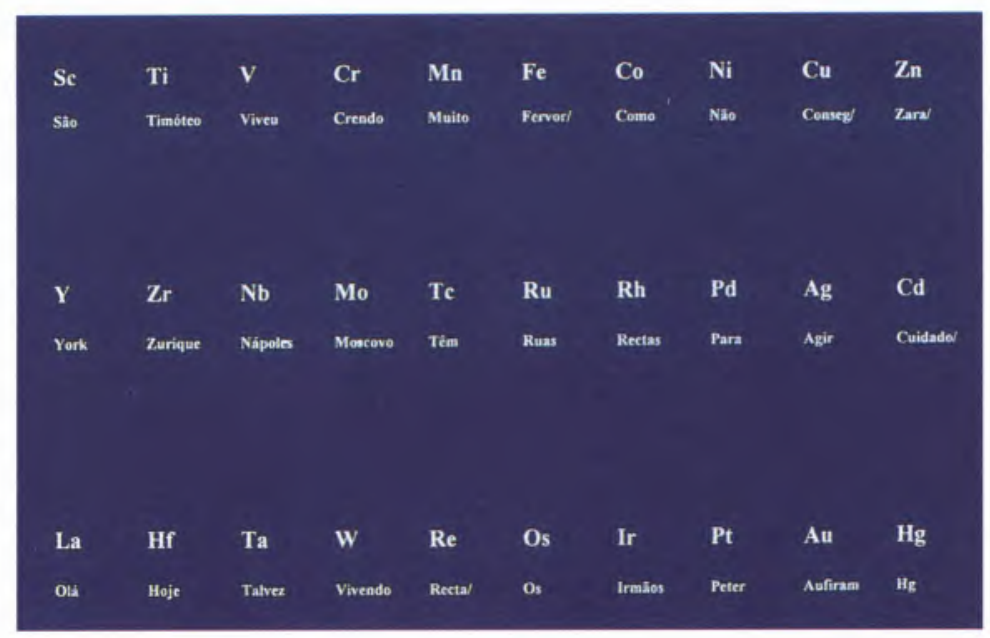

Fig 3. - A TABELA PERIÓDICA: As séries difíceis 
senvolvi lenga-lengas sem nexo para as aprender, género "São Tomás Viveu Crendo Muito Fervorosamente Como Não Conseguiu Zaratustra" (por outros símbolos, Sc, Ti, V, Cr, $\mathrm{Mn}, \mathrm{Fe}, \mathrm{Co}, \mathrm{Ni}, \mathrm{Cu}, \mathrm{Zn})$; ou ainda, "York, Zurique, Nápoles e Moscovo Têm Ruas Rectas Para Agir Cuidadosamente" - Figura 3. E percebi as regras, daí saber, também de cor, quase todos os números atómicos e os números de massa.

São processos ingénuos e primitivos de espevitar a memória. Só muito mais tarde travei conhecimento com os fabulosos palácios de memória, essas construções barrocas mentais de génios como o Padre Matteo Ricci que vingou na China depois de ter passado por Goa e Macau. Ricci (1552-1610) era aparentemente capaz de escolher ao acaso 500 ideogramas chineses e de os repetir de trás para a frente. Francesco Panigarola, que possivelmente ensinou Ricci em Macerata, dava-se ao luxo de vaguear por 100000 (sim, cem mil) imagens, cada uma memorizada no seu espaço próprio.

Ricci ensinou aos chineses as regras fundamentais da construção da sede da memória: cada lugar ou divisão devia ser espaçoso, mas não tão atafulhado de imagens que se corresse o risco de perder alguma (uma praça em dia de mercado ou uma escola cheia de estudantes não seriam imagens apropriadas); a luz devia ser clara e uniforme, mas sem encandear: os espaços tinham de estar secos e limpos; deviam ser escolhidos ao nível do chão ou um pouco acima, e não estar pendurados duma trave ou empoleirados no telhado. O olho mental devia poder deslizar confortavelmente duma imagem para outra, de modo que a distância entre elas nunca deveria ser inferior a três pés ou superior a seis.

O propósito destas construções mentais era fornecer espaços onde pudessem ser armazenados os milhares de conceitos que formam o conhecimento e experiência humana. Já S.Tomás de Aquino (1225-1274) tinha referido a importância das "se-

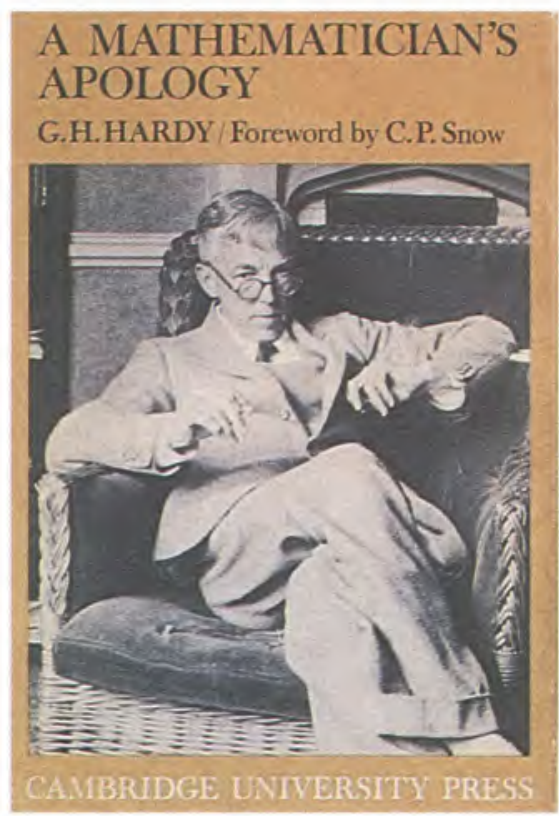

Fig. 4. - G. H. HARDY, A Mathematician's Apology.

melhanças corporais" (isto é, imagens de memória em forma corporal) para evitar que "coisas espirituais e subtis" escapassem da alma. O corpo é o suporte do espírito, e este pode ser concebido à imagem e semelhança daquele.

\section{OS LIVROS DE CABECEIRA}

A Defence of Poetry é um livro curto - pouco mais do que doze mil palavras. Quase todos os livros verdadeiramente importantes são pequenos (a observação não é minha, mas sim de Peter Medawar, um Nobel da Medicina e Fisiologia em 1960.) Convido-vos a fazer este exercício - seleccionar os vossos livros de cabeceira, pequenos. Os romances japoneses também são pequenos. A minha lista (dez títulos numa ordem arbitrária) aí vai:

\section{SHELley, A Defence of Poetry SHAKESPEARE, Sonetos AQUILINO RIBEIRO, O Malhadi- nhas}

G. H. HARDY, A Mathematician's Apology

P. MEDAWAR, Advice to a Young

Scientist

W. HEISENBERG, Física Nuclear

F. CRAMER, Caos e Ordem

PRIMO LEVI, A Tabela Periódica PUCHKINE, A Dama de Espadas F. PESSOA, Mensagem

Algumas notas: (i) Aquilino foi, creio, o primeiro grande escritor português que eu li (o segundo foi Almeida Garrett, o terceiro Júlio Dinis e o quarto Eça de Queirós - tudo antes dos meus dez anos). De Aquilino li primeiro $\mathbf{O}$ Romance da Raposa (1924) que ele escreveu para o filho, também Aquilino (e primeiro Presidente da Câmara de Lisboa democrática no pós - 25 de Abril): devia ter eu uns 5-6 anos, e lembrome de me deliciar com os sons das palavras que eu não entendia e que repetia em voz alta, assim descobrindo uma nova forma de música "pintalegreta", "lambisqueira", "peripatético", etc; (ii) Hardy, o grande matemático inglês, foi - é - um dos meus heróis, e não apenas por ter sido 'fellow' do meu colégio de $\mathrm{Ox}$ ford (New College) - Figura 4. No liceu estudei por um dos seus livros, o famoso A Course of Pure Mathematics (1908), então na $10^{a}$ edição. (iii) A Física Nuclear de Heisenberg (na edição inglesa) foi outro dos meus livros de liceu, e fundamental nas minhas opções de estudante e de carreira (a reforma curricular do Instituto Superior Técnico tinha introduzido uma boa cadeira de Física Atómica logo no $1^{\circ}$ ano). (iv) $\mathrm{O}$ meu desgosto de nunca ter aprendido russo está relacionado com a frustração de saber que Puchkine é intraduzível. Como aconteceu a outros, cheguei a Puchkine por via da ópera: Mussorgsky, Tchaikovsky, Rimsky-Korsakov. A Dama de Espadas é uma novela tão condensada, que coube numas 30 páginas. Tchaikovsky ainda condensou mais, e numa ópera de mais de $2 \mathrm{H} 45 \mathrm{M}$ tudo se resume a meia dúzia de compassos ansiosos, de partir a alma. (v) Escolhi o Conselho A Um 


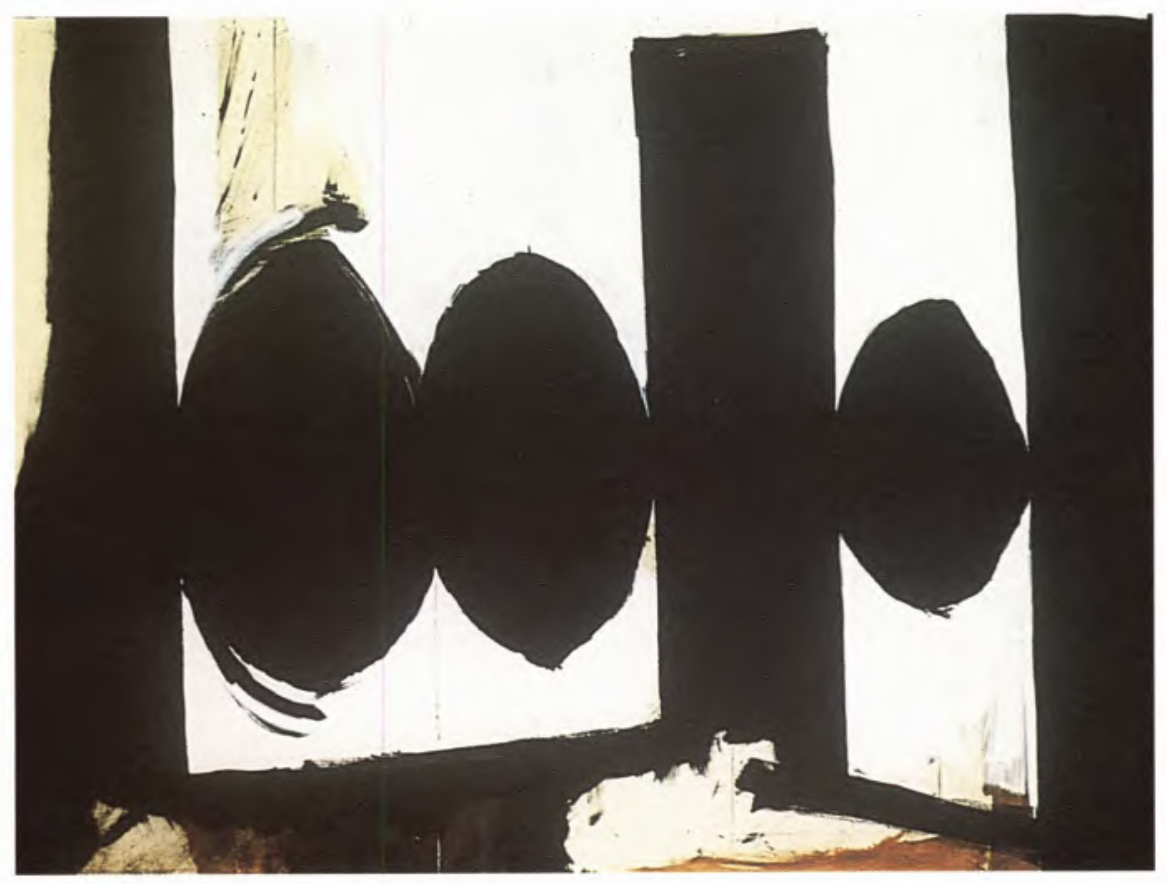

Fig. 5. - ROBERT MOTHERWELL, Elegy to the Spanish Republic (1957-61), Museum of Modern Art, Nova lorque

Jovem Cientista de Medawar, mas qualquer outro dos seus livros também podia integrar a lista. (vi) Quanto à Mensagem, aprendi com o meu Pai quase todos os poemas de cor, em especial o último, "Nevoeiro". Não o cito, para obrigar os mais desmemoriados a irem lê-lo outra vez; apenas noto que é por causa de coisas como esta que dizem que não sou patriota...

Noto agora, à data da revisão deste texto para publicação no Boletim da S.P.Q., que elaborei esta lista um ano antes da febre das listas - os melhores livros, as melhores pinturas, as melhores peças de teatro, os maiores músicos, etc - que assolou o mundo anglo-saxónico em 1998. É a febre do fim-do-século. E se é verdade que a escolha do Ulysses de James Joyce ou do Waiting for Godot de Samuel Beckett não parecem levantar grande controvérsia, já a escolha de Aretha Franklin como cantora do século é de causar engulhos.

\section{BREVE EXCURSÃO À REPÚBLICA ESPANHOLA}

Como disse Shelley, a Imaginação diz respeito às semelhanças entre as coisas, e a nossa missão, como professores, está em despertar a imaginação dos estudantes. Para detectar semelhanças, é preciso memória. ONDE É QUE EU JÁ VI ISTO? é, para um cientista, uma das mais belas perguntas que se podem fazer. Dou-vos um exemplo - o duma série de pintura de Robert Motherwell, intituladas Elegy to the Spanish Republic - Figura 5. Porque é que a pintura tem este título? What is it about? (Devo dizer que tentar compreender a arte moderna é um excelente exercício para tentar explicar a física moderna, da Distribuição de Maxwell-Boltzmann ao Princípio da Incerteza, ao conceito de Orbital. Deus escreve direito por linhas tortas ou, como dizia o Hamlet, "by indirections find direction out") Na obra-prima de Motherwell vejo a estrutura dum composto orgânico ramificado, mas detecto também as tensões entre a recta e as curvas; vejo os braços angustiados e estendidos das figuras da Guernica, vejo o luto (e como faz lembrar algumas belas imagens do fotoensaio de W. Eugene Smith, Spanish Village, 1951), ou os testículos e o falo do touro. Será que eu veria isto tudo na pintura se ela tivesse outro título. Claro que não. Mas o meu argumento é que ela não podia ter outro título.

\section{ONDE ESTÁ A MECÂNICA ESTATÍSTICA?}

Um professor de física do Instituto Superior Técnico, António da Silveira, começava as aulas de dúvidas com uma advertência: NO QUESTIONS ABOUT FUNDAMENTALS! Por outro lado, David Tudor disse a um estudante do famigerado Black Mountain College, "If you don't know, why do you ask?". O diálogo e a discussão só são possíveis numa base comum de assunções. Quando um estudante me diz que não entende um assunto complexo, eu respondo que o que ele ou ela não compreende é o simples. Coisas como o espaço ou o tempo, a estrutura do átomo, a pressão de vapor ou as temperaturas absolutas negativas. De facto, como dizia o Santo Agosti-

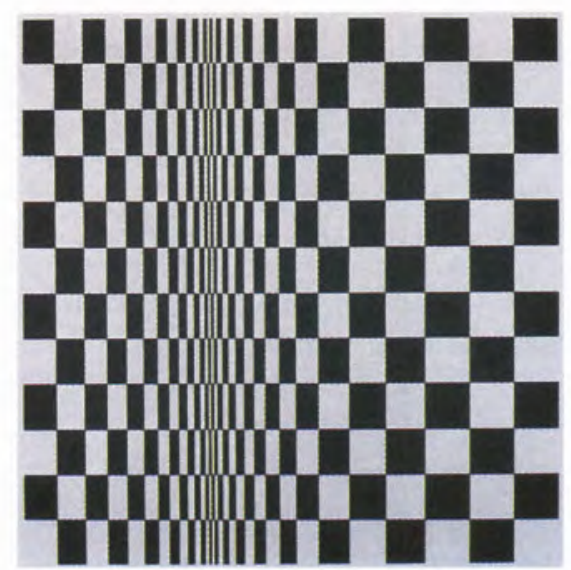

Fig. 6 - BRIDGET RILEY, Movement in squares, 1961, Arts Council of Great Britain 
nho, a gente não entende aquilo que quer saber, só entende o que não nos interessa. Se não me perguntas, eu sei; se me perguntas, eu já não sei. E, a propósito, as Confissões de Santo Agostinho talvez devessem figurar na lista dos meus livros importantes. Mas não é um livro pequeno...

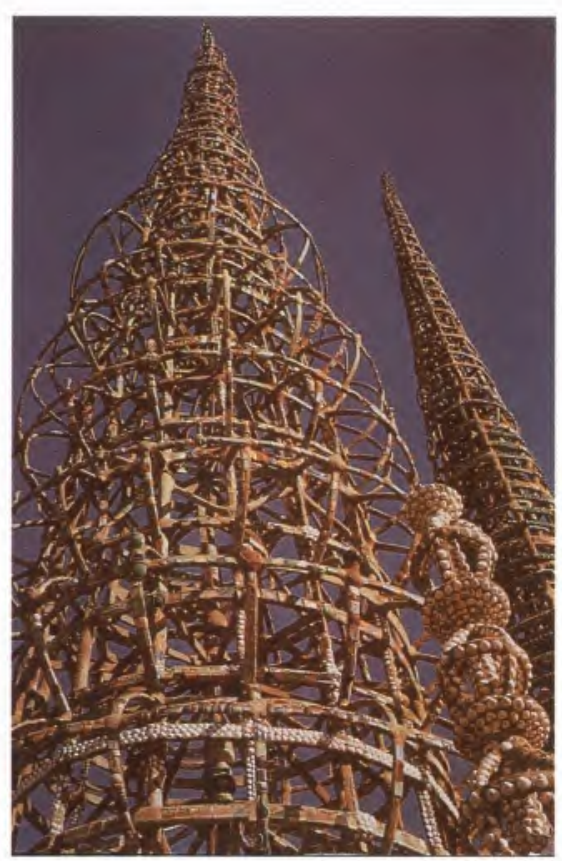

Fig. 7. - SIMON RODIA, Watts Towers, 1921-54

Volto a Shelley e à sua defesa da Poesia que nos "compele a sentir aquilo de que nos apercebemos, e a imaginar aquilo que sabemos. Cria de novo o universo, depois de ele ter sido aniquilado nas nossas mentes pela repetição constante de impressões embotadas pela reiteração". E volto, uma vez mais, a notar que esta é a linguagem da ciência. A arte e a ciência começam e acabam com a percepção. Arte e ciência são ambas actos de revelação. Como dizia Emerson, "o olho é o primeiro círculo".

Vou buscar outro exemplo à pintura, desta vez à obra duma pintora inglesa muito na moda nos anos 60 , Bridget Riley. Qualquer obra serve, por exemplo o Movement in squares, de 1961 - Figura 6.

Há qualquer coisa de clínico na superfície imaculada das suas pinturas. De certo modo, trata-se de superfícies anónimas, preparadas por assistentes sob a supervisão da pintora. (Estranho, já que qualquer manifestação de puritanismo é imprópria dos anos 60.) Mas o que me interessa - o que interessa a um químico-físico - é a influência nítida do conceito da digitalização, da linguagem binária do 0,1 (na pontilização e na alternância do branco e preto).

A digitalização ou a linguagem binária do sim-não afectam outras obras fulcrais dos anos 1960s como o Blow-Up (1968) de Michelangelo Antonioni ou o edifício do World Trade Center em Nova Iorque; a opção por um par de torres - em vez do orgulho solitário de arranha-céus tradicionais como o Empire State Building - persistiu até aos nossos dias, com as Petrona Towers em Kuala Lumpur. Subjacente à pintura de Riley está uma concepção atómico-molecular da matéria, também visível no impressionismo e, mais ainda, no pontilismo de Seurat; há ainda uma dinâmica que vem do fu- turismo italiano. Por outras palavras, trata-se de Mecânica Estatística feita pintura. E, a propósito, como exercício de lucubração, onde estão os equivalentes da Mecânica Estatística na mais sólida e estável de todas as artes - a arquitectura? Estão em obras como o Palácio Ideal (começado em 1879) de Ferdinand 'Facteur' Cheval em Hauterives (a cerca de $60 \mathrm{~km}$ de Lyon) ou nas casas e igrejas de Gaudí em Barcelona; estão ainda nas Watts Towers (1921-54) de Simon Rodia, em Los Angeles Figura 7.

A arte de Riley é também uma pintura próxima da música (de acordo com Motherwell, a pintura moderna aproximava-se cada vez mais da música), talvez de Stravinski, de quem ela admirava The Poetics of Music.

Tal como sucedera a Ucello com a perspectiva e a Picasso com o cubismo, também Riley atacou os modos normais de percepção. Riley preocupa-se com a expressão física de estados de tranquilidade psíquica, ou de tensão e desequilíbrio. Os elementos com que trabalha são a forma, a densidade (no sentido da densidade numérica ou número de

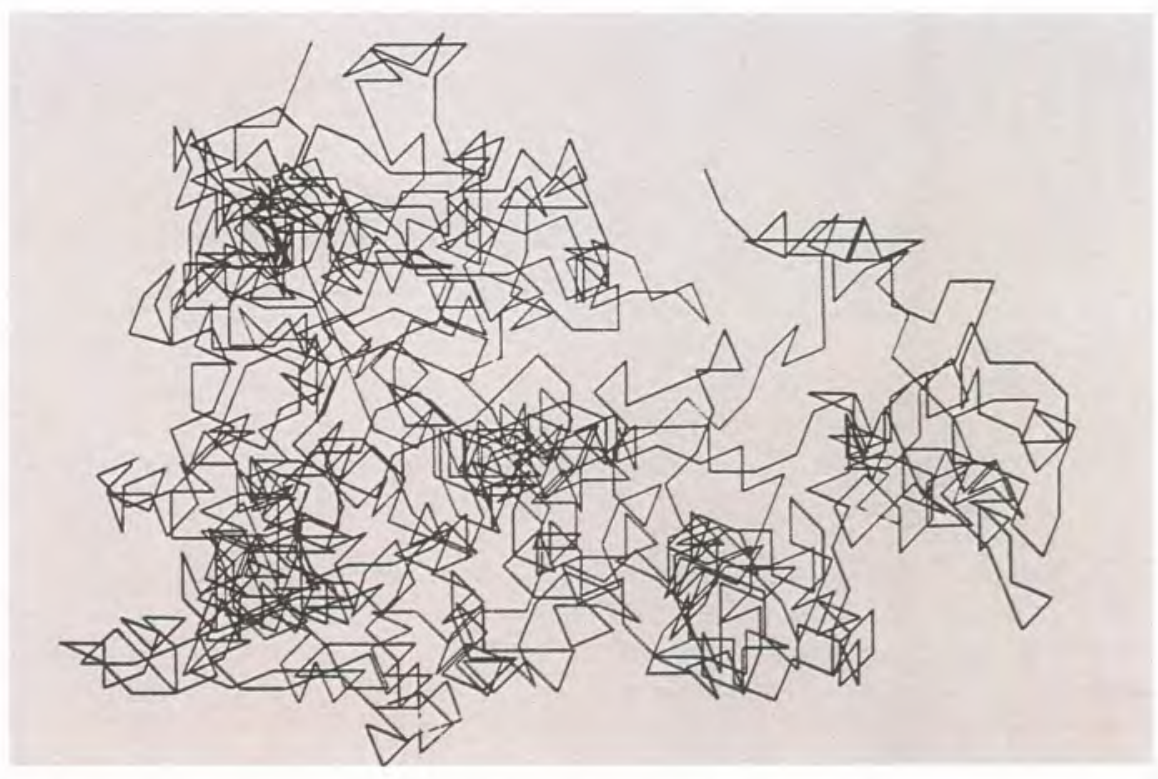

Fig. 8. - VITZ, Long random walk, 1966 


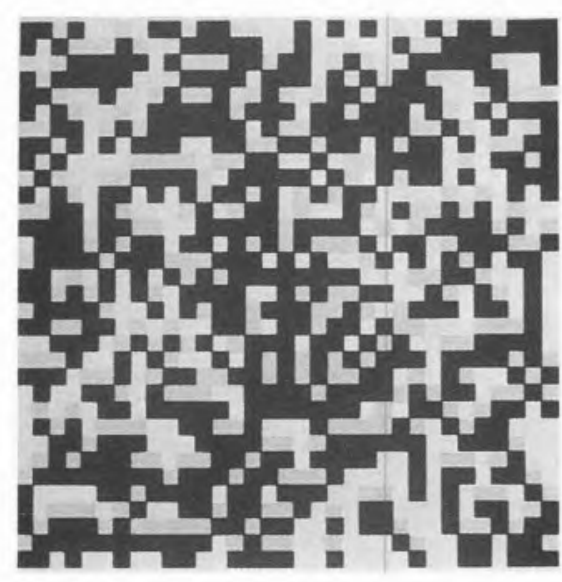

Fig. 9. - BÉLA JULESZ, Random-dot stereogram, 1971

partículas por unidade de volume da já evocada mecânica estatística), a velocidade-direç̧ão, em último recurso, a côr. É uma pintura que envolve o espaço, não o espaço da tela mas sim o espaço bem mais dramático que separa o quadro do seu observador. Aproximamo-nos e afastamo-nos da tela para experimentar os efeitos de percepção, tal como uma partícula a explorar um campo de forças. Desde Michael Faraday que não se via nada como isto...

\section{PERCEPÇÃO E MEMÓRIA}

Para terminar, alguns exemplos de ciência e arte que exploram os mecanismos da percepção e memória. Vou buscá-los ao aleatório, ao caos e à desordem. O interesse por estes temas atravessa o século XX. com dois fortes picos: um no princípio do século e outro, mais elaborado, nos anos 50-60. O primeiro está ligado aos estudos do movimento browniano (Einstein) e o segundo à teoria da informação. Foram estes desenvolvimentos que permitiram aos psicólogos perceptuais usar, de maneira sistemática, processos estatísticos aleatórios para a construção de estímulos visuais. O líder desta área foi Fred Attneave que introdu- ziu as formas aleatórias em estudos perceptuais. Por exemplo, Paul Vitz, professor de psicologia na New York University, usou trajectórias aleatórias tipo 'random walk' em experiências sobre a preferência em função da complexidade do estímulo.

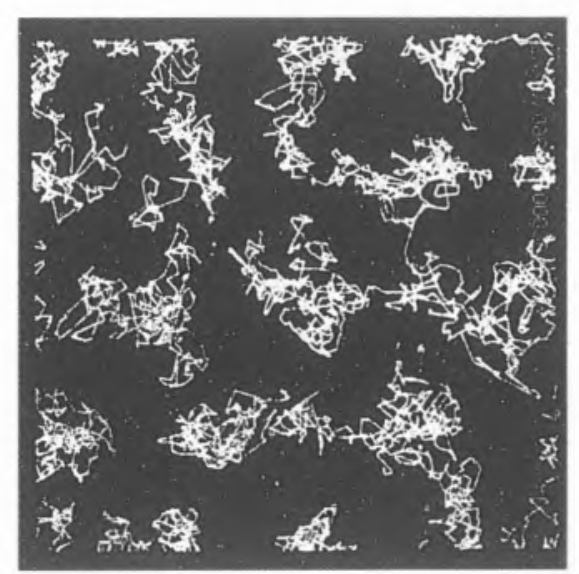

Fig. 10. - ALDER E WAINWRIGHT,

Percursos de 32 partículas depois de 3000 colisões (estado fluido)

Na Figura 8, segue-se um segmento de recta que pode ser prolongado em cada uma de 8 direç̧ões aleatórias; ao fim de 1000 passos o aspecto é o seguinte (há reflexão no limite da esquadria). Os equivalentes poéticos encontram-se em Stéphane Mallarmé (que uma vez disse que um poema era só palavras), e equivalentes musicais em Pierre Boulez. Oiça-se o Pli selon pli, 1957-1962 (Improvisation I, "Le vierge, le vivace et le bel aujourd'hui") onde a altura dos sons parece ser imprevisível (tal como o movimento browniano).

Fred Attneave usou igualmente polígonos estrelados aleatórios em estudos de percepção. O curioso é que estas formas apareceram independentemente e na mesma altura na obra de pintores tão diversos como Kandinsky e Matisse. Igualmente as estruturas ('pattern') de pontos ou quadrados aleatórios que Attneave concebeu nos anos 50 (por exemplo, uma lista de números ale- atórios determinava, na base do parímpar, uma de duas cores possíveis numa quadrícula) tiveram sucessores na obra gráfica de artistas como Béla Julesz - Figura 9. Uma tal obsessão quadriculada lembra o rigor cartesiano das pinturas de Mondrian. Julesz, nos EUA, usou o computador para gerar uma série de números aleatórios; François Morellet em França usou a lista telefónica para o mesmo efeito, e assim criou a sua Distribuição aleatória de 40000 quadrados, $\mathbf{5 0} \%$ branco, $\mathbf{5 0} \%$ preto (1961). Parece tudo muito infantil - a maldição que pesa sobre a arte moderna - ou dadaista, e é. (Tal como o nome indica, DADA antes de ser um movimento foi um balbuciar de bé-bés). E que dizer dos primeiros cálculos de Dinâmica Molecular para a fusão, efectuados por Berni Alder e Thomas Wainwright em 1959? - Figura 10. Podia ser uma experiência de psicologia de Attneave ou Vitz ou um quadro de Jackson Pollock. É, afinal, um dos trabalhos seminais de Química-Física.

Se não tivesse memória, se não tivesse retido todos estes factos singulares e díspares, não os poderia correlacionar. A ciência, que mais do que Razão é Imaginação, é a arte das associações universais. Por outro lado, a maior parte dos fenómenos interessantes (e importantes) são evolutivos. Há bifurcações, pontos de fulguração. Os fenómenos adquirem uma história, uma memória. A ciência deixou de ser previsível mas é explicável, a posteriori. Mas para recordar o passado é preciso memória. Mas isso é outra história - não a história da memória, mas a memória da história.

\footnotetext{
t Adaptado duma palestra proferida na Sociedade Portuguesa de Química, Lisboa, a 3 de Junho de 1997.
}

* Centro de Quimica Estrutural, IST, 1049-001 Lisboa 


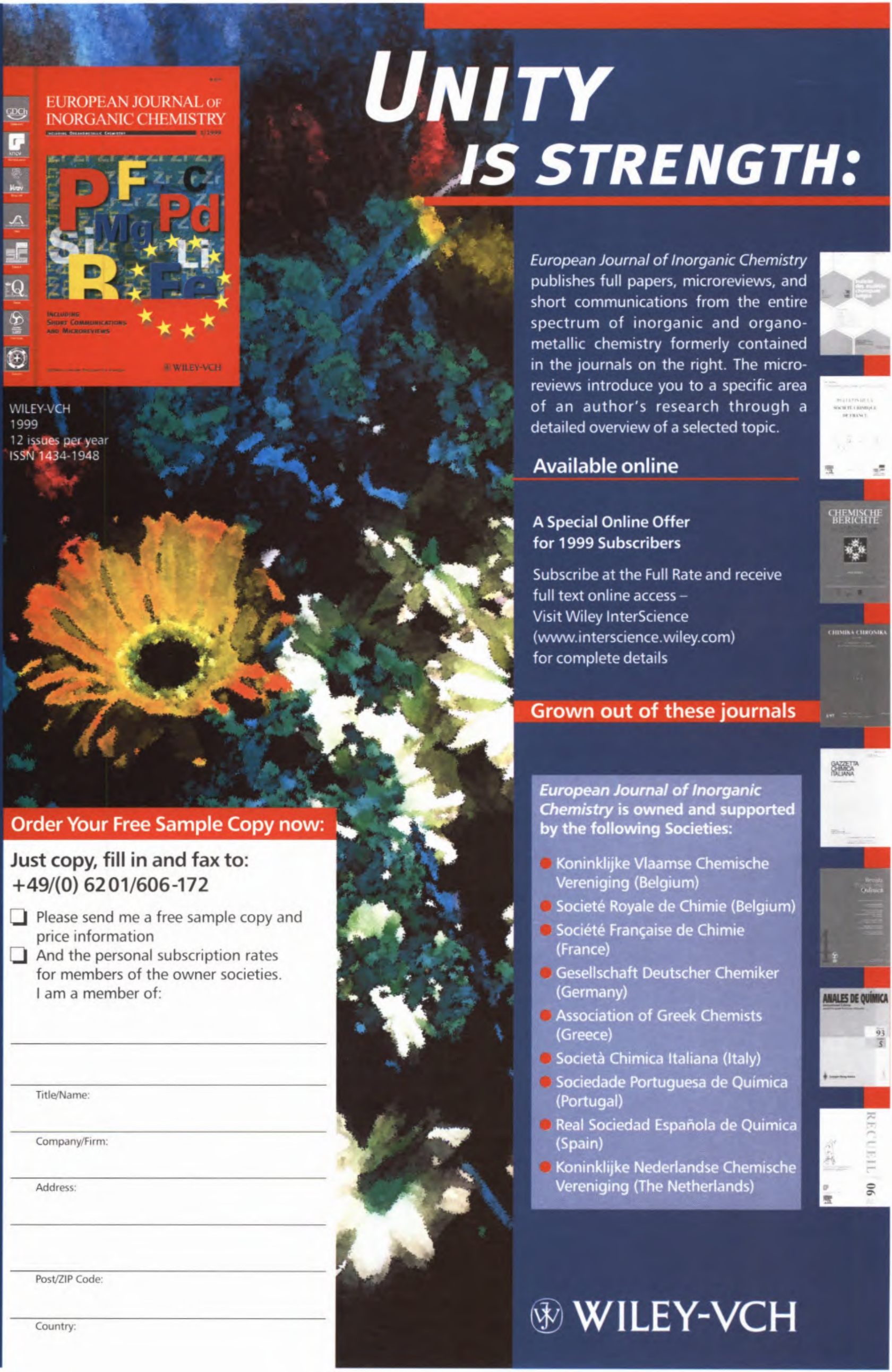

